\title{
QUALITY OF LIFE OF PREMATURE INFANTS TREATED WITH SURFACTANT AT 18 MONTHS OF LIFE: OUTCOMES FROM THE NEOACQUA STUDY
}

\author{
F. Bianco ${ }^{1}$, G. Cremonesi ${ }^{1}$, R. Montirosso ${ }^{2}$, R. Borgatti ${ }^{2}$, NEO-ACQUA Scientific Board \\ ${ }^{I}$ Medical Department, Chiesi Farmaceutici, Parma, ${ }^{2}$ Neurorehabilitation Unit, IRCCS 'E. Medea', Bosisio \\ Parini (LC), Italy
}

Background and aims: This post hoc analysis was performed as part of the multicenter, prospective observational trial NEO-ACQUA (NEOnatal Adequate Care for QUAlity of Life), with the aim of investigating QOL in the first 18 months of life of very preterm infants treated or not with surfactant and infants born at term.

Methods: Study population is described in the table. Only premature infants without documented neurological pathologies/deficits were enrolled.

\begin{tabular}{|l|l|l|l||}
\hline & $\begin{array}{l}\text { Group A Premature } \\
\text { Treated with surfactant }\end{array}$ & $\begin{array}{l}\text { Group B Premature Not } \\
\text { treated with surfactant }\end{array}$ & Group C Born at term \\
\hline $\mathrm{N}$ & 89 & 61 & 145 \\
\hline $\mathrm{BW}$ (grams $\pm \mathrm{SD})$ & $1067.9 \pm 242.1^{*}$ & $1236.0 \pm 189.3$ & $>1500$ \\
\hline Apgar & $7.3 \pm 1.6^{*}$ & $8.4 \pm 1.0$ & $\geq 8$ \\
\hline [study group demographics] & &
\end{tabular}

$* \mathrm{p}<0.0001 \mathrm{~A}$ vs B

TAPQOL questionnaire has been performed at 18 months of age.

Results: Considering all TAPQOL domains $9 / 12$ in group A, 10/12 in groups B and C displayed a 75 th percentile of the score equal to 100 , meaning that $25 \%$ of the infants achieved the highest value. Only the motor function was statistically different between group $\mathrm{A}$ and $\mathrm{C}(\mathrm{p}=0.0007)$ but not between group $\mathrm{A}$ and $\mathrm{B}$. In all three groups the 75 th percentile of the motor domain was 100 , whereas the 25 th percentile was 83.3 (A), 87.5 (B) and 93.7 (C).

Conclusions: TAPQOL questionnaire showed that QOL at 18 month among the three groups considered is comparable, in spite of a lower BW and Apgar score in premature infants treated with surfactant. This evidence need to be confirmed by the forthcoming follow-ups.

On behalf of: NEO-ACQUA scientific board: M. Agosti, R. Bellú, G. Calciolari, MC. Cavallo, A. Del Prete, R. Zanini 